DILEME O VSEBINI IN POLOŽAJU REGIONALNE GEOGRAFIJE V SISTEMU ZNANOSTI

Vladimir Klemenčič

IZVLEČEK

UDK $910.1: 913$

Avtor razvija misel o potrebnosti regionalne sinteze ob upoštevanju naravnih in družbenih elementov $\mathrm{v}$ njihovi medsebojni soodvisnosti.

ABSTRACT

UDC $910.1: 913$

THOUGHTS ON POSITION AND CONTENTS OF REGIONAL GEOGRAPHY IN THE SYSTEM OF SCIENCE

The author develops thoughts on needs of regional synthesis where physical and social elements should be brought into an adequate interdependency.

V zadnjih dveh desetletjih se med geografi v Sloveniji in po svetu mnogo razpravlja o vprašanju "regionalne geografije". Gotovo je vzrok za "kritično" stanje regionalne geografije vse manj novih knjig in razprav, ki bi obravnavale posamezne regije, države ali večje pokrajinske enote po klasičnih kompleksno regionalnih geografskih metodah. Hkrati pa lahko sledimo geografskim študijam posameznih prostorskih ali regionalnih enot, ki ne nosijo naslova geografija tega ali onega območja, ampak največkrat problemsko zasnovano obravnavajo določeno zaključeno geografsko tematiko in njen naslov.

Tako se pojavljajo pod različnimi imeni geografske monografske študije, imamo jih že tudi za SR Hrvatsko, SR Makedonijo, v tisku pa je tudi takozvana "Landeskunde Bayern". V čem je torej razlika med problemsko zasnovano in klasično pojmovano regionalno geografijo? Po mojem ne gre zavračati nobene od teh dveh smeri, kajti vsaka ima svoj namen in cilj. Ne moremo pa razlike teh dveh konceptov opredeliti, ne da bi osvetlili razlike $\mathrm{v}$ funkciji, vsebini in teoretično metodološkem pristopu geografije, ki je značilna za prostor statične agrarne družbe na eni in prostor moderne dinamične industrijske družbe na drugi strani.

* Dr., univ. prof., Oddelek za geografijo, Filozofska fakulteta, 61000 Ljubljana, Aškerčeva 12. 
Zavedati se moramo, da je od konca 19. pa do 80. let tega stoletja geografija ustrezno družbeno tehnološkemu razvoju in njegovim učinkom na oblikovanje prostora prešla kar pet faz: kozmografsko, družboslovno, morfološko, funkcionalno in procesološko. V teh fazah družbenega razvoja je zato morala tudi geografija bistvęno spremeniti svoj položaj v okviru znanosti in menjati svoj način dela. Od opisovanja je morala preiti $\mathrm{h}$ kvantitativnim in kvalitativnim analizam, ki terjajo uporabo moderne tehnologije raziskovalnega dela $\mathrm{z}$ računalniki in vključitev $\mathrm{v}$ sistem delitve dela $z$ novonastalimi prostorskimi vedami. Žal pa pogosto še vedno ostajamo $\mathrm{v}$ geografiji pri statičnem, strukturnem in opisnem načinu dela, kar nas ne vodi k regionalno-geografski osvetlitvi realne podobe in funkcije pokrajine višje razvite družbe. (Slika 1).

Ce dosledno upoštevamo naloge geografije ali njeno definicijo, da bi naj bila "veda, ki obravnava posamezne fizično-geografske in družbenogeografske elemente $\mathrm{v}$ njihovi medsebojni povezanosti in razvoju ter navezanosti na prostor", moramo priznati, da ne morejo tej nalogi več zadostiti $\mathrm{v}$ celoti niti posameznik niti posamezne skupine geografskih raziskovalnih inštitucij. Č nočemo geografi ostati amaterji, moramo upoštevati rezultate tako naravoslovnih kot družbenih ved. Prav zato, ker niti posamezniki niti skupine pri današnjem načinu organizacije raziskovalnega dela ne morejo obvladovati novega znanja posameznih disciplin ali skupnih spoznanj naravoslovja in družboslovja, se je geografija morala odločiti za problemski pristop, to je $\mathbf{k}$ geografsko teoretično in metodološko zasnovani raziskavi prostorsko relevantnih pojavov pokrajine ali prostora. Pri tem pa menim, da je njena naloga, da sprotí sledi novonastalim in nastajajočim prostorskim ali regionalnim pojavom, ki jih odpira proces družbenogospodarskega in tehnološkega razvoja. Seveda ji pri tem ostaja naloga razvijanja metodologije za pripravo monografskih študij, ki pa imajo večinoma le strokovni, ne pa znanstveni značaj. Pri tem delu morajo geografi upoštevati rezultate drugih znaností, nekatere pojave pa morajo tako kot doslej obravnavati le $\mathrm{z}$ opisovanjem. 


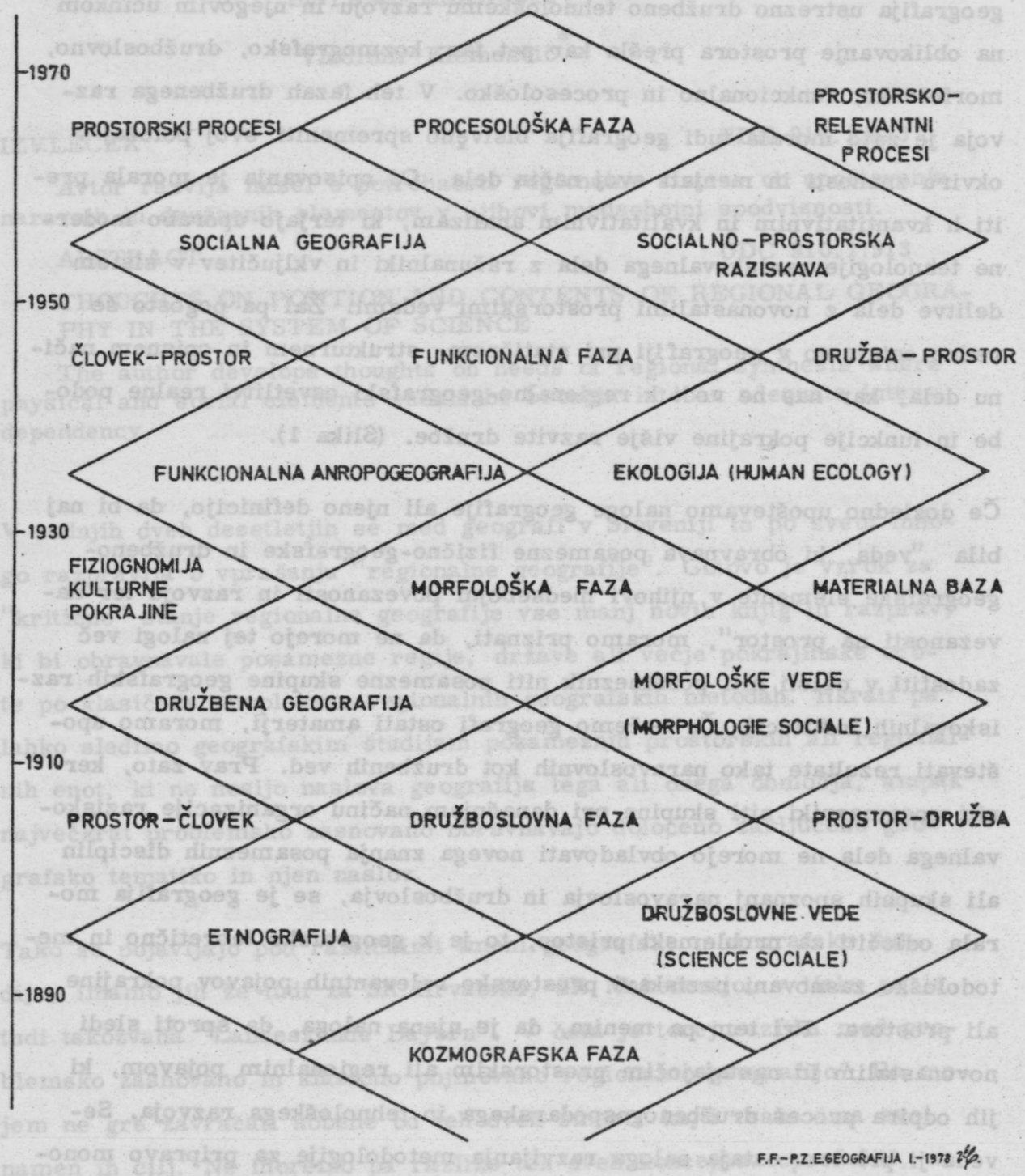

PREGLED NAD DRUŽBENO-GEOGRAFSKIMI IN EMPIRIČNO-SOCIOLOŠKIMI FAZAMI RAZVOJA ZNANOSTI (PO THOMALE-ju 1972) $-16-$ 
V moderni industrijski družbi postaja pokrajina in prostor direktno ali indirektno predmet vrste drugih disciplin, saj tudi druge stroke pojavov ne morejo obravnavati izven prostora in izven družbe. Tako sledimo oblikovanju novih vej znanosti, ki snujejo svoje delo prostorsko in regionalno, zlasti $\mathrm{v}$ sociologiji, ekonomiji, ob oblikovanju nove vede ekologije, ki jo tako kot $v$ geografiji pojmuje vsaka stroka na svoj način.

Ob takem razvoju pojmovanja in funkcije geografije se odpira vprasanje kaj lahko pojmujemo pod "geografijo" ali "regionalno geografijo". Pri tem se srečamo z različnimi definicijami, ki so največkrat subjektivne narave. Gotovo ne moremo označevati nobenega dela za geografskega, če ne izhaja iz iskanja zvez med človekom in družbo ter naravo. Ker vsebuje vsaka pokrajina ali vsaka regija svoje specificnosti in svojstven sistem medsebojne povezanosti le-teh in $\mathbf{s}$ tem tudi svojstven učinek povezanosti teh elementov na oblikovanje pokrajine, se problemsko zasnovana geografija s sistemskim pristopom postopoma vsebinsko oddaljuje od stare klasične opisne regionalne geografije.

Prav gotovo pa moramo ločiti takozvano regionalno geografijo nam oddaljenih kontinentov ali dežel od regionalne geografije ožjega obmocja, za katerega smo v stanju opraviti lastne raziskave določenih pojavov, a hkrati tudi s terenskim delom ugotavljati učinke dejanske povezanosti in soodvisnosti clovekovega dela $\mathrm{v}$ določeni družbi in določenem prirodnem okolju na oblikovanje pokrajine od tiste regionalne geografije, ki sloni na kompilaciji virov geografske in negeografske narave in $\mathrm{ki}$ jih avtorji nikoli niso mogli terensko obiskati ali proučevati. Ko imamo v mislih regionalno geografijo, ki sloni zgolj na opisih ali le deloma na terenu geografsko proučenih pojavov, se moramo zavedati, da se v poljudnem tisku vse bolj pojavljajo tudi razne enciklopedije in statistični prikazi o družbeno in fizičnogeografskih pojavih za posamezna območja. Mnogo novih informacij dobivamo tudi $v$ dnevnem časopisju, na radiu in televiziji. 
Vprašanje nastaja, kako je z regionalno geografijo v Sloveniji. V zadnjih tridesetih letih lahko zasledimo geografske studije, ki jih lahko razvrstimo po aspektih in zasnovah $\mathrm{v}$ vंeč skupin. V disertacijah, ki jih je opravila danes že starejša generacija slovenskih geografov ob koncu 60. in $v 70$. letih so individualna dela vezana na določeno regijo v Sloveniji, v kateri se klasiěni regionalni pristop že prepleta s problemskim. Večina doktorantov je skušala ob osvetlitvi fizičnogeografskih elementov kot materialne osnove za življenje osvetliti tudi nove procese, ki so bili povezani z začetki urbanizacije podeželja glede na doseženo stopnjo urbanizacije in glede na uveljavljanje novih gospodarskih in negospodarskih dejavnosti in njim ustrezne poselitve ter strukture prebivalstva. V 80. letih pa že moramo slediti večjemu poudarku ali pa bolj specializiranim študijam bodisi posameznih elementov ali celotnega kompleksa družbeno in fizičnogeografskih elementov. To je doba, ko smo se v Sloveniji že srečali s tako intenzivnimi procesi urbanizacije ali razvojem posameznih neagrarnih dejavnosti, da so že dobivale svoj odraz $\mathrm{v}$ podobi in funkciji kulturne pokrajine. Po mojem smo to fazo razvoja regionalne geografije in geografije na sploh $v$ Sloveniji relativno dobro opravili, nismo pa prešli $\mathrm{k}$ poskusom višjih oblik na teamski osnovi zasnovanih regionalnih analiz. To fazo bomo lahko opravili $s$ povezovanjem dela in rezultate nosilcev raziskav posameznih elementov ali kompleksa fizično in družbeno geografskih elementov, z uporabo moderne tehnologije in ob upoštevanju teoretskih in metodoloških izhodišč regionalne geografije po svetu ter spoznanj naravoslovnih in družboslovnih znanosti. Takemu poizkusu moremo slediti pri uveljavljanju prostora socialnogeografskega sitema. V dunajsko-münchenski socialnogeografski šoli so že sami avtorji tega sistema (K. Ruppert, F.Schaffer, H. Bobek, W. Hartke, E. Thomale, J.Maier, R. Paesler) pokazali na vrzeli pri proučevanju tako nekaterih elementov fizičnogeografske kơt družbenogeografske narave (Slika 2 in 3 ). Pri tem se je pokazalo, da morajo geografske raziskave temeljiti na dobrem poznavanju procesov uveljavljanja gospodarskih in negospodarskih dejavnosti in na usposobljenosti geografa za sprotno zaznàvanje novega načina soodvisnosti in povezo- 
SKUPNOST INFORMACIJSKEGA SPEKTRA

DOJEML JIVE IN SELEKCIONIRANE INFORMACIJE
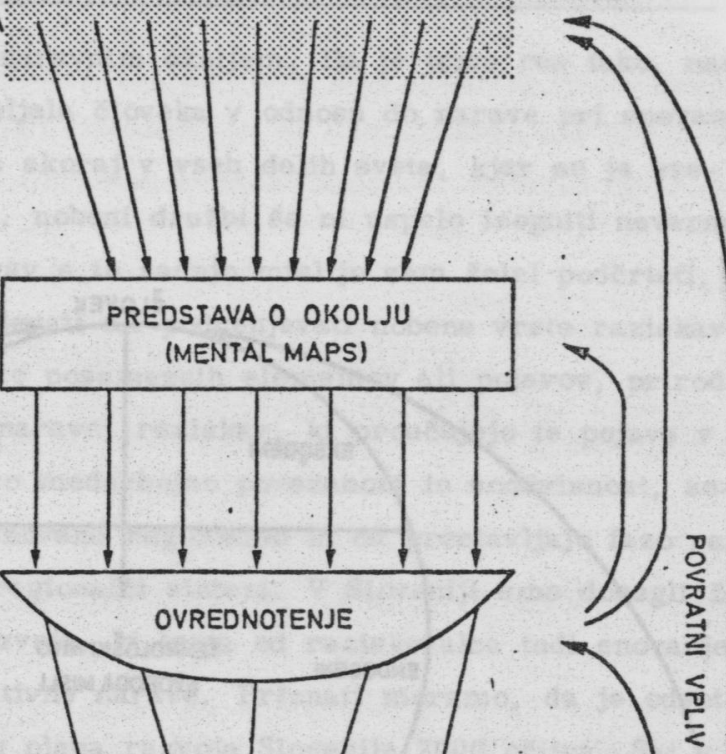

OVREDNOTENJE INFORMACIJ

PROSTORSKO UČINKOVITE DEJAVNOSTI ZNOTRAJ BAZIČNIH FUNKCIJ

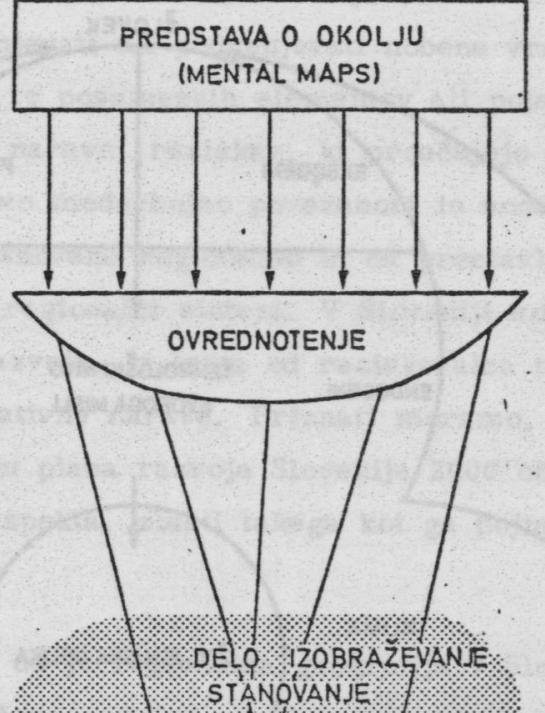
PREDSTAVA O OKOLJU

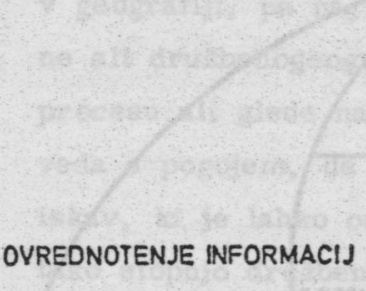

\section{BAZICNH FUNKCIJ}

KRAJINSKI VZORCI

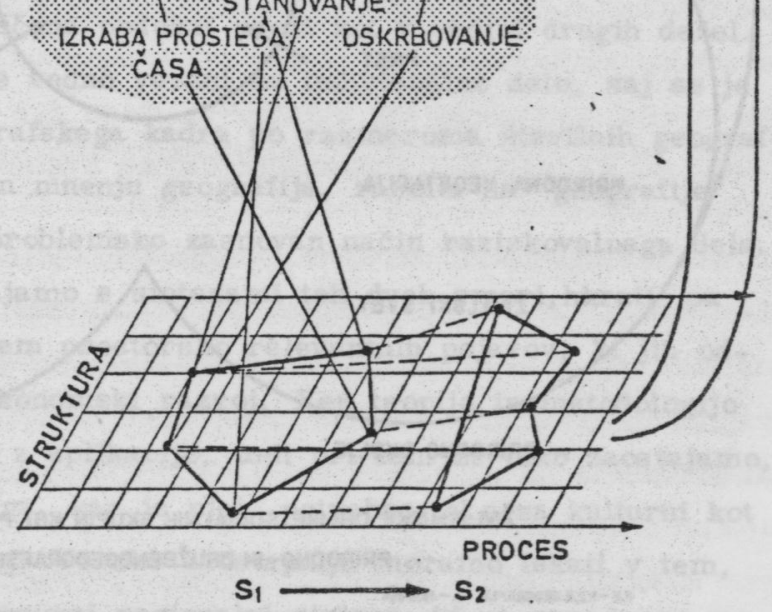

SPREMENJEN KRA JINSKI VZORCI IN ODNOSI

SOCIALNO-GEOGRAFSKI PROSTORSKI SISTEM (PO K. RUPPERTU) 


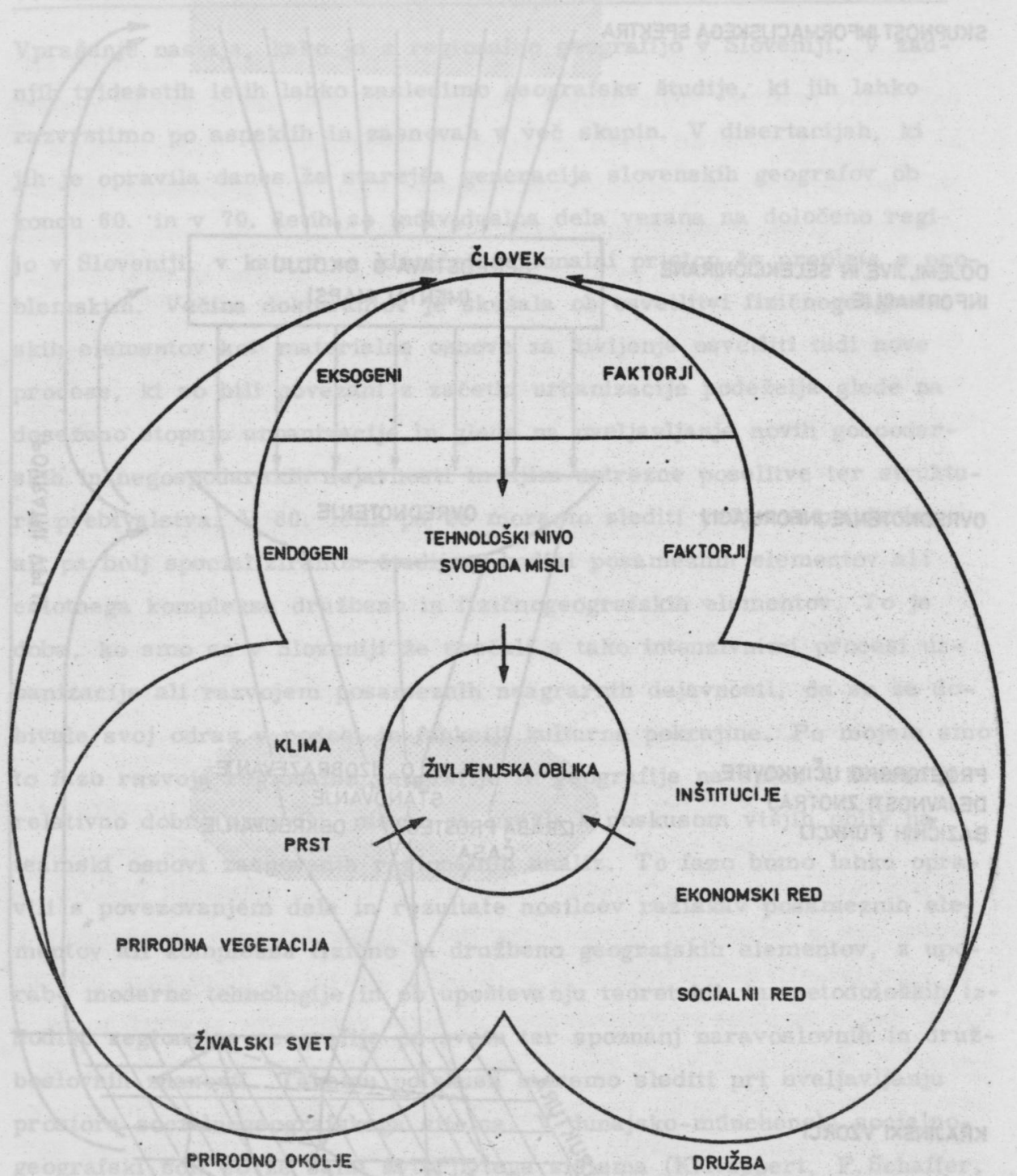

ŽNNLIENUSKE OBLIKE SOCIALNIH SKUPIN KOT PREOMET ANALIZE PRIRODNO-IN DRUŽEENOGEOGRAFSKHH FAKTORJEV 
vanja človeka in družbe $z$ naravnim okoljem. Da je temu res tako, nam potrjuje stiska, ki je pripeljala človeka $\mathrm{v}$ odnosu do narave pri snovanju družbenega razvoja, saj se skoraj $\mathrm{v}$ vseh delih sveta, kjer se je uveljavila moderna tehnologija, nobeni družbi še ni uspelo izogniți nevarnosti ekološke katastrofe. Prav s to zadnjo mislijo sem želel podčrtati, da ne kaže ovirati, precenjevati ali podcenjevati nobene vrste raziskav v geografiji, pa naj si bo to posameznih elementov ali pojavov, prirodne ali družbenogeografske narave, raziskav, ki proucujejo te pojave $\mathbf{v}$ procesu ali glede na njihovo medsebojno povezanost in soodvisnost, seveda s pogojem, da so zasnovane regionalno in da prestavljajo fazo raziskav, ki je lahko osnova regionalni sintezi. V Sloveniji smo dosegli že tako stopnjo družbenega razvoja, ki terja od raziskovalca tudi snovanje geografskih raziskav aplikativne narave. Priznati moramo, da je odsotnost geografov pri snovanju plana razvoja Slovenije 2000 očitna. Saj v tem planu, prostorskega aspekta, zlasti takega kot ga pojmujemo $v$ geografiji, ni zaznati.

Že v uvodu sem poudaril, da je regionalna geografija $v$ Sloveniji v zadnjih dvajsetih letih prepuščna podobni usodi kot $v$ večini drugih dežel. Ker smo v veliki meri še vedno vezani na individualno delo, saj se je kljub močni zasedbi geografskega kadra po razmeroma stevilnih geografskih inštitucijah po mojem mnenju geografija, razbila na "geografije" in "geografijice" ter na problemsko zasnovan način raziskovalnega dela. Po mojem pri tem zaostajamo s sintezami teh dveh smeri, hkrati pa tudi s sprotnim odkrivanjem prostorsko relevantnih pojavov, ki jih odpira dinamičen družbenoekonomski razvoj. Ker teorijo in metodologijo ne povezujemo vedno tudi $z$ aplikacijo, tudi pri tem že tako zaostajamo, da ne nudimo družbi tistega, kar je njej potrebno tako za kulturni kot družbeno ekonomski razvoj. Vzroke zaostajanju moramo iskati $\mathrm{v}$ tem, ker premalo težimo k takozvani regionalni sintezi, ki pa seveda ne more sloneti na opisih posameznih pojavov, temveč $v$ iskanju takih zvez med elementi družbenoekonomskega procesa, ki se odraža $v$ načinu izrabe naravnih danosti ali pa že od človeka preoblikovane kulturne po- 
krajine. Vse premalo smo posvetili pozornosti proučevanju smotrnosti, skladnosti ali nesmotrnosti in neskladnosti razvoja in funkcije zunanje podobe in funkeije prostora odnosno pokrajine.

Ceprav že dvajset let bolj ali manj sistematično raziskujemo Slovenijo v okviru raziskovalnih programov, ki jih finansira Raziskovalna skupnost, se še do danes nismo mogli zediniti, kako bi sistematično izbirali in proučevali slovensko pokrajino, da bi nas privedlo do take sinteze, ki bi jo potrebovali pri usmerjanju take rabe slovenskega prostora, ki bi odgovarjala pestrim in raznolikim potezam obalnega, kraškega, alpskega, predalpskega in panonskega sveta.

DER STAND DER REGIONALEN GEOGRAPHIE IM SYSTEM DER WISSENSCHAFTEN UND DIE DIESBEZUEGLICHEN INHALTLICHEN DYLEMMAS

Im Aufsatz wird die Entwicklung der regionalen Geographie und Inhalt und Methodologie vorgestellt. Berücksichtigt wird die Bereich der klassischen, statischen agraren und der dynamischen, urbanen Gesellshaft. Dabei wird besonders der veränderte Stand der geographischen Wissen * schaft im Rahmen des wissenschaftlichen Systems berücksichtigt.

Es wird festgestellt, dass die Geographie der Gegenwart mit anderen Disziplinen, z.B. der Oekologie, aber auch mit den Wirtschaftswissenschaften und der Soziologie das Forschungsobjekt teilt. Die Geographie in Slowenien hatte die Phase der so g: "beschreibenden Regionalgeographie" schon überwunden sie verblieb jedoch in der problemorientirten Geographie ohne, dass sie sich für eine komplexe Regionalanlyse zu organisieren versucht. Die Aufwertung der Geographie auf die Ebene der regionalen Analyse kann nur im Rahmen eines "Teamworks" geschehen wobei moderne Technologien, die Computertechniken eingeschlossen werden müssen. 